\title{
EDITORIAL
}

\section{Los resultados de la Segunda Encuesta Nacional de Nutrición. Las condiciones de nutrición de la niñez y de las mujeres de México}

L a aparición, hace un año, de la vasta monografía en la que el Instituto Nacional de Salud Pública diera a la luz colectiva los resultados de la Encuesta Nacional de Nutrición 1999, constituyó entonces uno de los acontecimientos relevantes en el terreno de las ciencias de la salud. Al igual que como antes sucediera con la primera Encuesta (1988), la pormenorizada información publicada, así como la que directamente puede obtenerse de los bancos de datos en los que aquella se sustenta, representan desde entonces obligativa referencia y fuente de citación, si bien esto principal y casi exclusivamente entre expertos y estudiosos a profundidad de tópicos concretos, tanto en el ámbito biomédico como en el sociomédico. En cambio, a otros pudiera la documentación primicial parecer un tanto abstrusa, y su estudio asaz demandante.

En algún otro espacio, el autor ha profesado su profunda admiración ante el esfuerzo portentoso que significa el levantamiento de las dos Encuestas Nacionales de Nutrición que hasta el momento ha conducido el Instituto Nacional de Salud Pública. Esfuerzo que por lo visto ha rendido frutos gracias a la oportunidad de haberse conformado un multivariado y multidisciplinario equipo de profesionales, claramente motivado hacia el proyecto, dotado con devoción institucional, vocación científica, y todavía más que de experiencia, de lo que llamaríamos experticia. Seguramente ha sido inmenso el empeño y la lucha por conjuntar recursos de todo orden, incluidos desde luego los pecuniarios, que habrían de ser invertidos en los diseños conceptual, muestral y operativo, en la capacitación y estandarización del personal, y en la coordinación de tantas actividades. Con la ventaja de contarse ahora con excelentes procedimientos de exploración y de toda una parafernalia informática y analítica, como la que hoy día se halla a disposición del trabajador en ciencias de la salud.

Los diez trabajos originales que hasta el momento han emanado de la Segunda Encuesta se publican ahora reunidos, bajo la figura de un suplemento monográfico de Salud Pública de México. Se mantiene así la unidad conceptual e informativa original, en cuanto se respetan los requisitos del escrito en cuestiones de ciencia. Como fruto de investigaciones científicas que son, así publicados los resultados de la Encuesta responden a los típicos hábitos de lectura de quienes tienen a la literatura profesional periódica de elevado impacto como su principal fuente de información, a la vez que de fructífero intercambio intelectual entre colegas. Con el mérito adicional de poder así reconocer de modo puntual el nombre y la índole concreta de la contribución de cada uno de los investigadores que participan en el levantamiento de la encuesta y en el proceso de análisis crítico de la información obtenida. Pero sobre todo, escritos los artículos de esta publicación monográfica en idioma inglés, se brinda a la colectividad científica internacional la posibilidad de ilimitado acceso al conocimiento integral de la metodología y de los hallazgos de la Encuesta.

No siempre ha ocurrido así. En buen número de censos y encuestas, realizadas en diversos países, es común que los trabajos científicos originados en tales ejercicios aparezcan diseminados en publicaciones de muy variada índole, y a menudo años después del documento primicial.

Comprendidos en esta publicación la mayoría de los rubros abarcados por la Encuesta, acertadamente se les ha adjudicado un orden que se halla a tono con la reconocida ilación de los procesos vitales, en un entorno de posibles secuencias, consecuencias, y reper- 
cusiones operativas. Grato resultado de ello es que la lectura de la publicación se disfruta como si se tratara de los capítulos de un libro cientifico.

Atinadamente, este número incluye un artículo especial que da razón de la metodología usada en esta encuesta probabilística, así como de la tasa de respuesta a la misma. Ha de tomarse en cuenta que si bien el propósito obliga a procedimientos correctamente estandarizados y validados, a menudo es necesario adaptarse a peculiaridades poblacionales, incluidos los ahora tan protegidos "usos y costumbres", que han ameritado detallada descripción.

A primera vista, de los diferentes trabajos se gana la impresión de que poco ha variado el panorama que ya habían revelado investigaciones anteriores, o sea, que con la excepción del área metropolitana capitalina, desde las perspectivas económica y epidemiológica, la línea imaginaria del Trópico de Cáncer y la falla geológica de los $19^{\circ}$ dividen a la República Mexicana en tres franjas casi horizontales, cada una de ellas caracterizada por tasas distintivas de lo que se conoce como pobreza, o más bien "pobritud", con perdón por tal licencia.

En efecto, se colige de esta serie de artículos, que tal polarización geo-socio-médica se ve matizada, entre otras condiciones de vario orden, por un menguante ingreso económico, ruralismo, indigenicidad, y al menos durante la niñez, también femineidad. Testimonio de lo cual lo son, con ciertas excepciones y en ocasiones inesperadamente, las tasas diferenciales en la ingestión de macro -y micronutrimentos, observadas tanto en niños preescolares y escolares como en mujeres adolescentes y adultas; que se expresan en la elevada prevalencia de talla baja (que no "desmedro"), particularmente en niños de cultura indígena; en los patrones actuales de lactación materna; o en el estatus orgánico de zinc, yodo y, sobre todo, hierro, condición que se refleja en inaceptablemente elevadas tasas de anemia, predominantemente ferropriva. Dicho sea de paso, en poco difieren éstas de las que por los años 50 habían encontrado Luis Sánchez Medal y colaboradores, a lo largo y ancho del espectro socioeconómico. Segmentación que también se expresa, si bien cuantitativamente en sentido opuesto, en los elevados coeficientes de sobrepeso corporal y de declarada obesidad, en regiones predominantes mas no exclusivamente distinguidas por los menores índices de deprivación social y económica. Porque "la especie humana es un mosaico de estructuras corporales", según palabras de
Luis Alberto Vargas. Así, desde antaño el estereotipo biotipológico del mexicano y de la mexicana, de la edad preescolar en adelante, corresponde a un personaje segmentariamente voluminoso. Estructura y composición del tejido adipose varían con el sitio anatómico, y también con los patrones de consumo, sobre todo de lípidos. Fuerza es pues reconocer que en última instancia, más anormal resulta ser Don Quijote que Sancho Panza, y que es obligado distinguir la "obesidad del pobre" de la del rico.

Hábil y atinadamente, en la gran mayoría de estos artículos figuran las lógicas recomendaciones que se derivan de los originales hallazgos de la Encuesta. En el caso de la alarmante deficiencia de hierro, como también es el caso de otras carencias específicas, la oportuna instrumentación de las medidas preventivas y correctivas idóneas, podría y podrá reflejarse en resultados satisfactorios en un relativamente breve plazo. No ocurre así en lo que concierne a cualesquiera de los dos polos de la mala nutrición crónica.

Los investigadores aceptan la definición en boga de la desnutrición de larga evolución en niños: longitud o estatura inferior a la mediana registrada en estratos sociales que gozan de óptima salud, con peso corporal adecuado para la talla, aunque en toda forma deficitario respecto a la normal en términos de la edad del niño. El fenómeno que da lugar a esta disparidad antropométrica fue en su tiempo interpretado por Rafael Ramos Galván como expresión de homeorresis, modificando así en cierta medida la definición original de Waddington. Por otra parte, no es la persistente alimentación inapropiada del niño la única causa de reducción en la tasa de crecimiento lineal, sino que también pesan factores como la herencia, ligada o no a etnicidad, el abandono o maltrato emocional, ciertos factores de orden climático, y sobre todo, el hacinamiento de individuos. Fenómeno este ultimo cuya notoriedad claramente va en ascenso, como corolario sociológico de la actual diferencia entre la reducción de las tasas de mortalidad general y de natalidad.

Sin que de ello pueda caber duda, este tesoro bibliográfico da y dará para mucho. De igual modo que ocurre con la Encuesta de la que deriva, va a ser objeto, a escala internacional, de intensivo estudio, análisis y discusión en foros de muy variada naturaleza. La salud pública mexicana ha dado, una vez más, buena razón de su excelente desempeño.

Silvestre Frenk*

\footnotetext{
* Unidad de Genética de la Nutrición. Instituto de Investigaciones Biomédicas, Universidad Nacional Autónoma de México-Instituto Nacional de Pediatría, Secretaría de Salud
} 